\title{
Pesquisa: Chave do Problema de Pessoal
}

\author{
Hugh TAYLOR $\left({ }^{*}\right)$ \\ Tradução de MARY CARDOSO
}

$\mathrm{O}$

GovÊRno Federal não assenta em nenhuma base estatistica sólida suas atuais politicas de administração de pessoal. Já que os problemas decorrem dos conflitos de opinião em tôrno daquilo que constitui o significado real de uma politica, bem como no que toca à liberdade de ação que se deveria admitir nos esforços desenvolvidos para pô-la em prática, parece que se torna imprescindivel o estabelecimento de uma base firme, seja fundada em têrmos estatísticos, seja em outro tipo de evidência igualmente válida. Mais precisamente, parece necessário examinar cada pormenor de uma politica, obter dados concretos sôbre os resultados que o Govêrno poderá esperar de cada aspecto em particular e. com base em tais elementos, estabelecer questões típicas de flexibilidade de interpretação a admitir e de proporção de esfôrço a empregar, nas várias áreas abrangidas pela política de que se trata, tanto pelos funcionários de linha, quanto pelo "staff" especializado de pessoal. É óbvio que não pode haver certeza de que a pesquisa garanta a solução do problema; não obstante, a importância daquilo que está em jôgo mostra que vale a pena fazer a tentativa. Um resultado melhorará a eficiência, o moral e o prestígio do serviço federal, ao mesmo tempo que economizará boa parcela do dinheiro dos contribuintes. É possivel garantir que nenhum plano de pesquisa bem projetado e bem orientado jamais resultará em falência total e, sendo assim, mesmo que só se consiga atacar o problema principal com sucesso relativo, pelo menos será possivel ficar sabendo o que convém e o que não convém fazer no sentido de um esforço intensivo de aperfeiçoamento.

(*) Hugh Taylor foi, até pouco tempo, Chefe do Setor de Utilização de Pessoal, no Comando Militar Europeu, do Departamento do Exército, em Heidelberg, Alemanha. Foi professor da Universidade da Califórnia e, após trabalhos de pesquisa realizados tanto na indústria como em órgãos do Govêrno,prestou serviços no setor de pessoal, na Intendência do Exército. vindo a ser, mais tarde, Chefe da Divisão de Enquadramento, no Comando Europeu. 
Até aqui, não têm sido bastante eficazes os esforços feitos com vistas à análise e à solução efetiva do problema da administração de pessoal em seu conjunto, no serviço federal. Aceita-se, de modo geral, no círculo profissional especializado, a opinião de que há necessidade de mais pesquisa e de que novas perspectivas constituem parte necessária dessa pesquisa. Três grupos principais de pesquisa podem ser considerados: o primeiro - associações especializadas em pessoal - já preparou e vem executando, num programa não remunerado e não oficial de trabalho, amplas e positivas séries de planos de pesquisa sôbre as práticas federais em matéria de pessoal. Outro grupo prende-se a um programa oficial, executado por funcionários federais escolhidos e que tanto pode ser cumprido em tempo integral, como em tempo parcial de trabalho. A terceira categoria é representada por uma equipe de pesquisa de tempo integral, paga por individuos ou organizações dotados de espírito público.

Os programas de pesquisa encetados por associações profissionais representam admirável iniciativa, especialmente graças à experiência e à competência dos elementos que compõem os vários grupos de trabalho. Por outro lado, não deveriamos ser exageradamente otimistas quanto às possibilidades de amplas modificações como resultado da ação isolada dêsses grupos de especialistas. A amplitude da tarefa, que é o estabelecimento de principios e normas de administração de pessoal sistemáticos, sadios e razoàvelmente uniformes em todo o serviço público federal, bem como o grande significado dos objetivos visados com êsse trabalho, isto ê, a elevação dos niveis de eficiência, de moral e de prestigio do nosso serviço, requerem, evidentemente, a colaboração de muita gente em semelhante programa. É provável que ora se dediquem a tal empreendimento apenas umas poucas centenas de voluntários, que prestam sua colaboração em horas extras e que talvez constituam o grupo mais competente que se poderia reunir para um trabalho pioneiro de orientação. Mas, depois dêsse, deve vir o tremendo esforço de aplicar as linhas mestras que hajam sido traçadas - reunir casos para estudo e dados estatísticos, verificar tôdas as aparentes inconsistências, resumir tudo em conclusões firmes e objetivas, coordenar os resultados finais com todos os órgãos interessados. Isso exige tempo e dinheiro.

Deveria haver recursos públicos disponiveis para a execução de um tal programa, já que seus resultados deverão pagar, muitas vêzes, aquilo que possam custar, mas tem-se que admitir que não será fácil, nem rápido, conseguir verbas oficiais para êsses fins, visto que muitos membros do Congresso estão convencidos de que um projeto dêsse tipo viria a ser uma duplicação do trabalho já realizado pela Comissão Hoover. Mesmo que se obtivessem 
tais verbas, ainda haveria o risco do programa ser entregue à direção de altos funcionários do Govêrno sujeitos à influência de velhas tradições do serviço público, ou de velhos e novos grupos de pressão, o que privaria o trabalho da liberdade de ação e da firme objetividade que são elementos vitais de seu sucesso.

Uma solução que parece oferecer menos desvantagens seria a obtenção de cobertura financeira e de supervisão de um organismo do tipo da Fundação Ford. Não seria difícil a um patrocinador dêsses obter carta-branca para escolher determinados órgãos federais como áreas de pesquisa, além do que as conclusões obtidas através de um tal estudo mereceriam, sem dúvida alguma, a maior consideração e respeito.

A Associação de Administração de Pessoal preparou no ano passado a seguinte lista de tópicos:

1\%) Inquérito sôbre sistemas vigentes nos diferentes órgãos em matéria de enquadramento no trabalho.

2.) Papel desempenhado pelos sistemas atuais de avaliação do trabalho na administração de pessoal.

3:) Desenvolvimento de sistemas de promoção no serviço federal.

4\%) A classificação de cargos representa hoje a base mais segura para a elaboração das escalas de pagamento?

5.) Significado dos sistemas de incentivo como fator de aperfeiçoamento.

69) Como tornar mais compreensivel os padrões de classificação de cargos?

7) Padrões de lotação para a administração de pessoal.

8:) Meios de acelerar a remoção de funcionários inadequados.

9:) Formas práticas de enquadramento inter-departamental.

10) Treinamento de especialistas de pessoal.

11) Métodos de avaliação dos programas de pessoal

12) Técnicas para seleção de administradores.

13) Desenvolvimento de técnicas de análise de cargos.

14) Como organizar programas práticos de desenvolvimento.

15) Que parte da função global de pessoal deverá ficar a cargo do supervisor imediato?

16) Vantagem da existência de um colégio de administradores especializados no Govêrno Federal.

17) Treinamento em supervisão. 
Se considerarmos o número limitado de pessoas dedicadas à execução de tais estudos, admitiremos que a lista precedente não poderia ser mais prática, mas se se pudesse ampliar bastante o programa de pesquisa, muitos aspectos implícitos no trabalho atualmente feito poderiam ser examinados separadamente, ou seja, de uma perspectiva diferente, tornando possivel a obtenção de conclusões que poderiam ser tomadas como definitivas.

$\mathrm{O}$ aspecto que expontâneamente mais se impõe é a questão de saber porque é tão desalentado o apoio que recebem as politicas federais de administração de pessoal. Sabemos que falta de conhecimento, falta de habilidade e falta de coragem são amplamente responsáveis por isso. Mas não sabemos, ou pelo menos não podemos provar que sabemos, quais são os fatos importantes a considerar para suprir as falhas de conhecimento, habilidade e integridade profissionais, de forma realista. E entre as perguntas importantes a que uma adequada pesquisa poderia dar resposta estão estas: quanto, aproximadamente, a indecisão em matéria de politicas de pessoal custa ao Govêrno, em eficiência, ao Serviço Público Civil, em atração e prestígio, e ao povo americano, em-têrmos de dinheiro? Como se pode resolver eficientemente o problema da indecisão e que vantagens advirão disso?

Sabemos que tôdas as facetas da administração federal de pessoal necessitam de aperfeiçoamento. Podemos apenas fazer uma estimativa grosseira dos aspectos que mais reclamam essa melhora e dos meios mais práticos pelos quais podemos consegui-la - embora com a certeza de que nenhum aperfeiçoamento, de nenhuma espécie, pode ser realmente obtido sem que suas vantagens sejam inteiramente compreendidas, claramente explica. das e adequadamente transmitidas a tôdas as partes interessadas, através de esfôrço e apoio coordenados de todos os niveis de "staff" e de linha.

Cada um dos dezessete tópicos para pesquisa sugeridos pela Associação de Administração de Pessoal tem por objetivo examinar algum aspecto dêsse problema. Uma limitação de tal programa, porém, consiste em que o mesmo não prevê pesquisadores em número capaz de permitir o exame de problemas básicos comuns à maior parte, senão à totalidade, dos tópicos. Se isso pudesse ser feito, haveria dados de contabilidade de custo suficientes para comprovar os dividendos do investimento feito com a melhor demarcação de cada área separada de pesquisa. Fazemos ênfase neste ponto porque entendemos que os custos operacionais e os fatôres qualitativos que os influenciam parecem ser os dados mais necessários, quando se consideram as alterações a fazer nas práticas de pessoal principalmente porque são bastante objetivos 
para serem apreendidos pelo homem que pode fazer ou destruir qualquer programa de pessoal, ou seja, o supervisor.

O que se vai seguir é apenas um rápido esbôço, mas pode oferecer algumas linhas mestras no sentido da formulação de uma boa lista de tópicos para pesquisa:

1) Quanto custa um funcionário do tipo médio, que deixa o serviço? (O têrmo médio é usado aqui e nos parágrafos seguintes num sentido amplo, para evitar as longas definições técnicas).

2.) Quais os critérios usados, por quem e em que circunstâncias, a partir da chefia suprema dos departamentos, para avaliar, nos escalões operacionais inferiores, o progresso do programa de administração de pessoal estudado no curso da pesquisa? Com base nos resultados obtidos nesse estudo, é possivel dizer da validade dos critérios, da precisão das conclusões atingidas, do realismo das recomendações e da proporção em que estas últimas são aceitas e rigorosamente observadas? Que atitudes tomam a autoridade suprema, os altos funcionários e todo o pessoal de "staff" ante essas verificações?

39) Quais os principais obstáculos encontrados nos canais operacionais, na transmissão e na execução das práticas de pessoal aprovadas?

4\%) Quais os principais obstáculos opostos a uma coordenação real e ao entendimento entre os altos funcionários de linha e a equipe de pessoal?

5:) Que atitude, face ao programa de administração de pessoal, demonstram outros funcionários assessoriais cujas responsabilidades incluem as de "esclarecimento da administração", como os especialistas de organização e métodos de trabalho?

Como podem ser comparadas a implantação e a observância de novas políticas nesses campos com os mesmos procedimentos em matéria de administração de pessoal?

6?) Quais os aspectos do programa de pessoal que os funcionários entrevistados definem como "rotina burocrática"? Que tópicos os resultados da pesquisa colocaram sob essa classificação, inclusive aquêles que decorrem de mandamentos legais ou regulamentares? Qual a correlação existente entre as duas classificações?

7॰) Quais são os indicadores positivos de uma boa administração de pessoal? Qual, em média, merece maior e menor consideração e qual a obtem?

8:) Quais os indicadores positivos de boa assistência dos especialistas de pessoal? Qual, em média, merzce maior e menor consideração e qual a obtem? 
9:) Qual o "curriculum" educacional e de trabalho, antes e depois do exercício da primeira função supervisora, daqueles cujos resultados como administradores de pessoal são considerados notáveis? adequados? insatisfatórios?

10) Qual o "curriculum" educacional e de trabalho, antes e depois da nomeação, daqueles técnicos de pessoal cujo desempenho é considerado notável? adequado? insatisfatório?

11) Até que ponto os traços de personalidade ligam-se, consistentemente, à boa e à má atuação dos administradores de pessoal? à boa e à má assistência prestada pelo "staff" de pessoal?

12) Quais os requisitos de qualificação e os fatôres especiais de seleção observados ao se considerarem candidatos para cargos com responsabilidade de administração de pessoal? de assessoramento de pessoal? Que sentido real têm os mesmos, à luz da evidência apurada na pesquisa? Qual a correlação entre os indicadores de qualificação para cada tipo de trabalho, constantes dos registros do órgão de pessoal, e aquilo que foi apurado pela pesquisa, em matéria de bom e mau desempenho?

13) Qual a opinião dominante, quanto à eficiência das mulheres como supervisoras? como especialistas de pessoal? Até que ponto aquilo que efetivamente ocorre no exercicio dessas funções combina com a opinião geralmente predominante sôbre o assunto? Qual o resultado da comparaçãc entre os dois sexos, no tempo médio que permanecem a serviço do Estado?

Esta lista ainda nos deixa sem muitas repostas e definições. Por exemplo, que entendemos por boa e má administração de pessoal ou assistência dos técnicos de pessoal? No momento, êstes têrmos têm um sentido muito relativo, mesmo quando usados pelos pesquisadores dos programas de pessoal. Num determinado caso, bom significa apenas "muito melhor do que era, que era horrivel"; em outro, mau pode significar que tim excelente programa piorou muito, embora não de modo perigoso. A pesquisa deveria incluir retificações baseadas em aspectos típicos do desempenho, realisticamente identificáveis .

A resposta ao primeiro quesito da lista precedente - quanto custa ao Govêrno um funcionário do tipo médio que deixa o serviço, em têrmos de salários pagos sem serviços contra-prestados, nos períodos em que se estabeleceram as relações de emprêgo, em que se processaram o trabalho de orientação, o ajustamento ao ambiente profissional, o treinamento até a obtenção do rendimento máximo e, subseqüentemente, na fase de reduzido interêsse pelo trabalho, após a decisão de deixar o serviço do Estado - pode ajudar na enunciação de definições qualitativas, ao mesmo tempo que fornece dados sôbre custos. A razão da 
colocação de tal pergunta em primeiro lugar está em que a resposta respectiva nos poderá esclarecer de algum modo sôbre o procedimento capaz de garantir um mecanismo que retenha o empregado no trabalho e o mantenha em bon estado de rendimento. Dispomos de dados numéricos sôbre o equipamento mecânico que - Govêrno possui, como máquinas de escrever e automóveis e, porque dispomos de tais dados, podemos até certo ponto, de forma eficaz e sistemática, exigir a observância de determinadas normas oficiais para a compra, a manutenção, o reparo e a substituição dessas peças de equipamento. E por nos faltarem dados semelhantes sôbre nosso material humano, vamos sendo levados por tôda sorte de idéias pessoais sôbre como atrair, manter, reformar e substituir as peças dêsse outro equipamento.

A importância relativa de diferentes aspectos da assistência prestada pelos técnicos de pessoal foi acentuada na lista que mencionamos porque é freqüente ouvirmos o seguinte comentário: "Muitas vêzes temos que deixar de fazer o que é mais importante, porque nossas outras obrigações nos mantêm ocupados demais". A primeira reação a essa afirmativa é a convicção de que a pessoa que falou ou está muito confusa ou é muito incompetente, mas se examinarmos mais profundamente o assunto veremos que o fato assinalado constitui um problema, muito além do contrôle individual do técnico de pessoal. São tão imprecisos os verdadeiros contornos da questão da assistência dos especialistas de pessoal que as prioridades mais cuidadosamente estabelecidas, baseadas numa cautelosa estimativa de resultados finais prováveis, seriam capazes de deixar em dificuldade os técnicos que as procurassem seguir.

A verdade é que, até que efetivamente se consiga descobrir, numa ordem decrescente, quais os aspectos do problema que demandam prioridade, temos que continuar como até aqui - deixando que as pressões, e não as necessidades, dirijam nossas rotinas diárias. Êsse aspecto tem implicações amplas, que incluem. entre outras, a redistribuição do trabalho, mas oferece também à pesquisa pistas de bastante simplicidade, desde que as variáveis humanas possam ser isoladas e controladas. Por exemplo, uma análise do trabalho do grupo que executou tarefas tipicas que se mostraram bem orientadas, comparado com o de outro cuja atividade mostrou ser um êrro, deveria fornecer um conjunto valioso de indicações, na determinação de prioridades. Se os resultados da pesquisa permitissem o grupamento das várias atividades do "staff" de especialistas sob amplas epígrafes como "tem que ser feito", "deveria ser feito" e "conviria fazer, se houvesse tempo". muito se poderia corrigir em nossas atuais perspectivas. E para que não se corra o risco de deixar de atentar para o principal, 
deve ser lembrado aqui que êsse problema surge apenas por causa das diferentes opiniôes em tôrno daquilo que a politica traçada efetivamente exige.

Outro ponto também constrangedor é o que se refere à eficiência relativa das mulheres no trabalho de supervisores e de especialistas de pessoal. Em alguns departamentos, a ineficiência feminina constitui muitas vêzes uma opinião preconcebida e repetida oficiosamente por porta-vozes altamente colocados. O resultado é que candidatos masculinos sem qualquer qualificação freqüentemente levam a melhor sôbre mulheres superiormente habilitadas. Os esforços no sentido de relacionar tais julgamentos a pontos específicos e objetivos resultam, via de regra, em respostas vagas e a conclusão a que se chega é a de que a apreciação é menos baseada em análises de fatos do que em generalizadas reações emocionais. $O$ ponto importante é que a situação existe e se mantém - freqüentemente em lugares-chaves, e a despeito de determinações expressas contra discriminação - com o fervor do partidarismo político. Os resultados que a pesquisa obtivesse nesse campo deveriam servir ou para sugestões de revisão das determinações regulamentares ou para o sistemático esclarecimento dos funcionários de linha e de "staff", de todos os niveis.

Um programa de pesquisa do tipo que é aqui proposto requer uma equipe altamente qualificada, a determinação de amplos objetivos, estudos intensivos dêsses objetivos e a aceitação da noção de que a probabilidade dos aperfeiçoamentos está condicionada pelo arcabouço das limitações legais e regulamentares em vigor. Com que pessoal deveria ser feita uma tal pesquisa? claro que nenhum programa dêsse tipo poderia ser bem sucedido sem o auxílio de outros especialistas de administração além dos técnicos de pessoal, do mesmo modo que não prescindiria de psicólogos e estatísticos.

Os técnicos de pessoa! inclinam-se a descrer das conclusões a que, em matéria de sua seara, cheguem especialistas de outros setores administrativos. para os quais há outros aspectos de tanta importância que não lhes permitem dar atenção suficiente aos problemas humanos com que diàriamente se vê a braços o técn co de pessoal. Não constitui exagêro demasiado afirmar que todos os estudos até aqui feitos se ressentem de uma mútua desconfiança entre técnicos de administração. Os que foram executados pelos especial stas de pessoal refletem freqüentemente preconceitos conscientes ou inconscientes, falta de conhecimento das limitações decorrentes do uso de dados selecionados e interpretação pouco científica dos dados reunidos. Deve ser ainda acrescentado que tais estudos são, via de regra, projetos de pequeno porte, entremeados nas rotineiras exigências do trabalho normal dos res- 
ponsáveis por sua execução e cujo objetivo, em geral, é o de contribuir para a observância de praxes administrativas já aprovadas e divulgadas, após o insucesso de recursos menos formais de persuasão.

Os estudos realizados pelos analistas de administração desviam com demasiada freqüência a atenção para aspectos ligados à organização e aos métodos de trabalho, e incluem, como uma espécie de complemento decorativo, considerações de caráter psicológico. Em contraste com o que foi anteriormente notado, tais estudos constituem geralmente projetos bastante vastos e suas conclusões quase sempre dão ao aspecto de administração de pessoal um tom de finalidade que obscurece qualquer solução realista.

Quanto aos técnicos de orçamento e aos especialistas em rendimento, são via de regra encarados pelos especial.stas de pessoal como trancamente hostis e perigosos, 1sso porque êstes últimos viram, mais de uma vez, programas de qualidade, cumpridos à custa de um trabalho estafante da equipe de pessoal, serem sacrificados porque aquêles técnicos não têm sensibilidade para os fatôres indicativos de qualidade, o que os faz medir tanto os programas progressistas, como os inoperantes, pela mesma bitola. Mesmo o relatório Hoover, simpático aos círculos de pessoal, mostra fé excessiva em instrumentos de mensuração que não dis* tinguem devidamente a qualidade da operação. Em conseqüência, conclui com a afirmação sumária de que os órgãos de pessoal do Govêrno têm gente demais e recomenda a padronização, sem ter examinado primeiro as verdadeiras exigências do trabalho desempenhado pelos técnicos de pessoal e sem verificar a hipótese de que importantes e complexos problemas podem ser abundantes numa determinada área administrativa e aparecer raramente numa outra.

Qualquer aspecto do complexo problema aqui discutido é essencialmente psicológico e o programa de pesquisa a que fize. mos referência deveria haurir sua motivação e suas diretrizes nos técnicos de pessoal, que têm longa vivência na área de operações, o que lhes permite ver, sentir e reconhecer os traços essenciais da questão como um todo. Auxiliados por psicólogos e estatísticos, os especialistas de pessoal poderiam estabelecer áreas de amostra de fato representativas, planejar adequadas entrevistas-padrões e fornecer interpretação correta dos dados recolhidos, capaz de garantir a validade das conclusões.

Outra consideração essencial consiste em assegurar que a pesquisa, embora mantida dentro de limites razoáveis, seja con duzida de forma tão completa que seus resultados principais tenham base de absoluta firmeza. Existe o perigo sério de que alguns aspectos realmente significativos sejam relegados a um 
segundo plano. Por exemplo, os dados relativos aos problemas que aqui mencionamos são abundantes, nos estudos feitos na indústria, e o problema central decorre da adoção de normas e diretrizes originadas sobretudo nos estabelecimentos industriais. Não teria, contudo, significado algum experimentar com dados emprestados uma política emprestada, que não teria validade nas condições reais do trabalho do Govêrno. Se os resultados não fôssem conclusivos, a impressão geral que se teria seria a de que o problema principal não poderia ser resolvido mesmo quando atacado massiçamente por especialistas de alta competência.

A situação internacional deu a cada cidadão americano o senso do perigo e o forte desejo individual de fazer alguma coisa em defesa de nossas instituições. Atingimos o ponto em que nós, civis, desejamos e estamos prontos a exercer liderança, em nossa vida cotidiana. Assim sendo, o problema de pessoal do Govêrno assume um significado que ultrapassa seu sentido ordinário, em razão dos tempos em que vivemos, e suas implicações podem ser demonstradas com o exemplo de como se constitui e como opera um batalhão de artilharia. As fôrças de coesão dêsses notáveis agrupamentos não estão na compulsão da autoridade militar, nem no ardor do patriotismo; nem os jovens soldados que os compõem são sòmente, e todos êles, a nata da humanidade. A explicação é muito mais simples: define se um objetivo e tomam se tôdas as providências necessárias para alcançá-lo. O objetivo mais amplo é fornecer a cada artilheiro tôda a espécie de informação que lhe possa ser útil para desempenhar sua tarefa e despertar e manter nêle o desejo de responder acima e além daquilo que constitui o seu dever, quando assim o exigir a emergência. Os oficiais intensivamente treinados, na área militar, nas atividades equivalentes à administração de pessoal civil, recebem o recruta, verificam o que êle sabe e o que lhe deve ser ensinado, preparam-no cuidadosa e pacientemente, de forma tal que seu interêsse seja estimulado e seu aprendizado se faça mais rápido; instilam nêle um justo respeito por seus companheiros e superiores; examinam com êle seus problemas e o ajudam a resolvê-los e, por fim, conseguem fazer com que êle sinta orgulho de seu batalhão e da parte que no mesmo representa, apesar de tôdas as dificuldades e de todos os perigos e de seu desejo de autopreservação.

Tôda unidade militar tem "esprit de corps"; assim também tôda equipe civil, os dois grupos comprovando o principio de que a massa de subalternos tem tanto interêsse em sua organização e no sucesso dela quanto esta demonstra ter em seus auxiliares e naquilo que possam realizar - nem mais, nem menos. Se a organização e o treinamento dos batalhões de artilharia houvessem sido entregues a oficiais apenas durante os intervalos entre dispu- 
tas e discussões com os oficiais comandantes das companhias, êste estudo do problema da administração de pessoal civil não teria sido escrito, porque teriamos perdido a guerra.

A analogia, contudo, não é de todo exagerada. O teste de uma democracia não é feito nos enunciados de sua politica, repousa na aplicação humana de tal politica àqueles que são por ela governados. A maquinaria burocrática que caracterizou passados governos e que caracteriza os que atualmente se apresentam num avançado estágio de decadência, sugerem ao leigo um paralelo ameaçador. Necessitamos desesperadamente da fôrça nova que nos poderia ser acrescentada por uns dois milhões de vigorosos servidores públicos.

(In "Personnel Administration" Administração de Pessoal - Vol. 16, n 5, pág. 27 e segs.). 